Abstracta Iranica Abstracta Iranica

Revue bibliographique pour le domaine irano-aryen

Volume 42-43 | 2021

Comptes rendus des publications de 2019-2020

\title{
Yousef Moradi, Edward J. Keall. "The Sasanian Fire Temple of Gach Dawar in Western Iran: New Evidence"
}

\section{Barbara Kaim}

\section{(2) OpenEdition Journals}

Édition électronique

URL : https://journals.openedition.org/abstractairanica/51817

DOI : 10.4000/abstractairanica. 51817

ISSN : 1961-960X

Éditeur :

CNRS (UMR 7528 Mondes iraniens et indiens), Éditions de l'IFRI

Référence électronique

Barbara Kaim, « Yousef Moradi, Edward J. Keall. "The Sasanian Fire Temple of Gach Dawar in Western Iran: New Evidence" », Abstracta Iranica [En ligne], Volume 42-43 | 2021, document 6, mis en ligne le 30 décembre 2020, consulté le 02 janvier 2023. URL : http://journals.openedition.org/abstractairanica/ 51817 ; DOI : https://doi.org/10.4000/abstractairanica.51817

Ce document a été généré automatiquement le 2 janvier 2023.

Tous droits réservés 


\title{
Yousef Moradi, Edward J. Keall. "The Sasanian Fire Temple of Gach Dawar in Western Iran: New Evidence"
}

\author{
Barbara Kaim
}

\section{RÉFÉRENCE}

Yousef Moradi, Edward J. Keall. "The Sasanian Fire Temple of Gach Dawar in Western Iran: New Evidence”, Iran, 58(1), 2019, p. 27-40

1 En 1978, une mission canadienne travaillant dans le complexe archéologique de Qal'ehye Yazdegerd a mené une saison de fouilles dans Gach Dawar ou les vestiges du chahar taq et des pièces adjacentes ont été découvertes. Les nouvelles fouilles de 2007 ont permis de réexaminer les pièces initialement reconnues lors des fouilles canadiennes. La découverte d'un certain nombre des installations cultuelles à l'intérieur du chahar taq (une plateforme au centre de laquelle il y avait une cavité carrée avec un podium à quatre marches, probablement une base pour un autel du feu) indique explicitement que le bâtiment a été conçu comme un temple du feu. Derrière la plateforme se trouvaient quatre marches qui, selon les AA., permettaient à un prêtre d'accéder à l'autel du feu. La présence de ces marches, inconnues des autres temples de feu sassanides suggère qu'il existait une diversité de formes de cultes pratiquées dans des bâtiments de ce type. 


\section{AUTEURS}

BARBARA KAIM

Université de Varsovie 